\title{
Involvement of mast cells and microvessels density in reactive lesions of oral cavity: A comparative immunohistochemical study
}

\author{
Stephany Vasco Ferreira a , Flávia Caló Aquino Xavier ${ }^{a}$, \\ Maria da Conceição Andrade de Freitas ${ }^{\mathrm{b}}$, Fábio Daumas Nunes ${ }^{\mathrm{c}}$, Clarissa Araújo Gurgel ${ }^{\mathrm{a}}$, \\ Maria Cristina Teixeira Cangussu ${ }^{d}$, Manoela Domingues Martins ${ }^{e}$, Valéria Souza Freitas ${ }^{f}$, \\ Jean Nunes dos Santos ${ }^{\mathrm{a}, *}$ \\ a Laboratory of Oral Surgical Pathology, School of Dentistry, Federal University of Bahia, Salvador, Bahia, Avenida Araújo Pinho, 62, Canela, Salvador, Bahia \\ 40110-150, Brazil \\ b School of Dentistry, State University of Southwest Bahia, Jequié, Bahia, Brazil \\ c Laboratory of Molecular Pathology, School of Dentistry, University of São Paulo, Avenida Prof Lineu Prestes, 2227, Butantã, São Paulo, SP 05508-000, Brazil \\ d Department of Dental Public Health, School of Dentistry, Federal University of Bahia, Avenida Araújo Pinho, 62, Canela, Salvador, Bahia 40110-150, Brazil \\ e Department of Oral Pahology, School of Dentistry, Federal University of Rio Grande do Sul, Porto Alegre, Rio Grande do Sul, Brazil \\ ${ }^{\mathrm{f}}$ Department of Health, School of Dentistry, State Universitiy of Feira de Santana, Feira de Santana, Bahia, Brazil
}

\section{A R T I C L E I N F O}

\section{Article history:}

Received 25 January 2016

Received in revised form 27 April 2016

Accepted 17 May 2016

\section{Keywords:}

Mast cells

Angiogenesis

Oral reactive lesions

\begin{abstract}
A B S T R A C T
In view of the similarity of clinicopathological features between reactive lesions of the oral cavity, the objective of the present study was to investigate the density of MCs (mast cells) and microvessels in a series of these lesions. Thirty-seven cases of reactive lesions including fibrous hyperplasia $(\mathrm{FH}, \mathrm{n}=10)$, inflammatory fibrous hyperplasia (IFH, $n=10$ ), peripheral giant cell lesion (PGCL, $n=10$ ) and lobular capillary hemangioma $(\mathrm{LCH}, \mathrm{n}=7$ ) were investigated using immunohistochemistry for mast cell tryptase and CD34. For comparative purposes, central giant cell lesions ( $\mathrm{CGCL}, \mathrm{n}=5)$ were included. A higher MC density was observed in LCH (37.01), while CGCL exhibited the lowest density $(n=8.14)$. There was a significant difference in MC density when all reactive lesions were compared to CGCL $(p=0.001)$. The largest mean density of microvessels was observed in $\mathrm{LCH}(\mathrm{n}=21.69)$. The smallest number was observed in $\operatorname{CGCL}(n=6.24)$. There was a significant difference in microvessel density when the reactive lesions were compared to CGCL ( $p=0.003$ ). There was a significant and direct correlation between the density of MCs and microvessels only for IFH ( $p=0.048$ ) and CGCL $(p=0.005)$. A significant and direct correlation between the mean density of MCs and microvessels was observed when the reactive lesions were analyzed as a whole $(p=0.005)$. Our results suggest that mast cells contribute to the connective tissue framework and angiogenic function, as well as the development, of reactive lesions of the oral cavity, including FH, IFH, LCH and PGCL.
\end{abstract}

(c) 2016 Elsevier GmbH. All rights reserved.

\section{Introduction}

Mast cells (MCs) are mobile cells derived from bone narrow that circulate in the blood. These cells are found in all mucosa milieu and connective tissue, especially in perivascular areas [1].

\footnotetext{
* Corresponding author at: Laboratório de Patologia Cirúrgica - UFBA, Avenida Araújo Pinho, 62, Canela, Salvador, Bahia, 40110-150, Brazil.

E-mail addresses: stephanyferreira3@gmail.com (S.V. Ferreira), f.calo@uol.com.br (F.C.A. Xavier), fadnunes@usp.br (F.D. Nunes), gurgel.clarissa@gmail.com (C.A. Gurgel), cangussu@ufba.br (M.C.T. Cangussu), manomartins@gmail.com (M.D. Martins),valeria.souza.freitas@gmail.com (V.S. Freitas), jeanunes@ufba.br, jeanpatol@gmail.com (J.N. dos Santos).
}

Several authors have suggested MCs to be potentially fibrogenic since they secrete powerful mediators of fibrosis, such as histamine, cytokines, proteoglycans, heparin, hyaluronic acid, proteases, and growth factor [1-7]. Studies have shown the interaction of MCs with fibroblasts and their contribution to the synthesis of collagen in many diseases and pathological conditions, such as oral submucous fibrosis [3], scleroderma [7], skin fibrosis [8], gingival fibromatosis [9], and fibrotic changes in the minor salivary glands of patients with Sjögren's syndrome [10]. Mast cells have also been reported to be involved in tissue repair [11] and tumor growth [12,13].

MCs are particularly prominent around capillaries [1,11-16]. These cells are known to release a variety of factors that increase 
angiogenesis, such as vascular endothelial growth factor (VEGF), fibroblast growth factor (FGFs), transforming growth factor alpha (TGF- $\alpha$ ), transforming growth factor beta (TGF- $\beta$ ), and interleukin 8 (IL-8) [6]. Angiogenesis is a highly organized multistep process that involves not only the formation of blood vessels, but also the proliferation and migration of endothelial cells [6,17]. Hence, the dysregulation of blood vessel formation has an impact on our health and can contribute to the development of different disorders [17].

The oral mucosa is constantly subjected to external and internal stimuli. Therefore, it can manifest a variety of diseases, including inflammatory, neoplastic or reactive lesions. Reactive lesions of the oral cavity are non-neoplastic lesions characterized by similar clinical features [18-21]. Although clinical features contribute to the diagnosis of each lesion, microscopic analysis is required for the definite diagnosis $[19,23]$.

Reactive lesions frequently found in the oral cavity are fibrous hyperplasia (FH), inflammatory fibrous hyperplasia (IFH), lobular capillary hemangioma (LCH), and peripheral giant cell lesion (PGCL). Histologically, FH and IFH are characterized by hyperplasia in the epithelial lining and abundant collagen in addition to a variable amount of blood vessels, and the presence or absence of a chronic inflammatory infiltrate $[20,22]$. Lobular capillary hemangioma is a common reactive angiomatous proliferation that occurs on the skin and mucocutaneous membranes [24]. In contrast, PGCL consists of a proliferation of multinucleated giant cells amidst oval or spindle-shaped stromal cells, associated with blood vessels and extravasated red blood cells $[20,25]$. Although the reactive lesions described here have common etiological features, their growth vary and can often be exuberant [19].

We hypothesized that tryptase released by MCs stimulates the synthesis of collagen and angiogenic potential. This release could exert influence on the development of FH, IFH, PGCL and LCH. Therefore, the aim of this study was to perform an immunohistochemical analysis of the density of MCs and microvessels in these lesions. Although being considered a reparative or reactive process [26,27], central giant cell lesions (CGCL) exhibit aggressive growth and can cause massive destruction of the jawbones [28]. So, CGCL were included for comparative purposes.

\section{Material and methods}

The study was approved by the Ethics Committee of the School of Dentistry, Universidade Estadual do Sudoeste da Bahia, Jequié, Brazil (Protocol No. 128/2011-CAAE: 0107.0.454.000-11). Thirty seven cases of oral lesions were studied and included 10 cases of IFH, 10 of FH, 10 of PGCL and 7 of LCH. For comparative purposes, five cases of CGCL were included.

The histological diagnosis was revised and classified by an experienced oral pathologist (J.N.S), and those cases with histopathological resemblance to either CGCL or PGCL were distinguished using clinical and image data. The specimens were obtained from the archive of the Pathological Anatomy Service of the School of Dentistry, Universidade Federal da Bahia. Clinical data (gender, age, and location) were collected from the biopsy records of the service.

The paraffin-embedded specimens were deparaffinized in xylene (twice for $10 \mathrm{~min}$ ), rehydrated in absolute alcohol (twice for $5 \mathrm{~min}$ ) at room temperature, and cut into $3-\mu \mathrm{m}$ sections. For antigen retrieval, the sections were incubated in $1 \%$ trypsin at $37^{\circ} \mathrm{C}$ for $30 \mathrm{~min}$ (three cycles of $10 \mathrm{~min}$ each) for mast cell tryptase antibody (1:50, clone AA1, Dako Corporation, Carpinteria, CA, USA), and in citrate, pH 6.0, at $98^{\circ} \mathrm{C}$ for 40 min for CD34 antibody (1:50, clone QBEnd-10, Dako Corporation). Then, the sections were incubated with the primary antibody diluted in background-reducing solution (Dako Corporation) at $4{ }^{\circ} \mathrm{C}$ for $18 \mathrm{~h}$. The EnVision polymer (Dako
Corporation) was applied for $30 \mathrm{~min}$ at room temperature and the reaction was developed with 3,3-diaminobenzidine (Dako Corporation) as chromogen for $5 \mathrm{~min}$ in a dark chamber. The sections were counterstained with Harris hematoxylin. Actinic cheilitis specimens with known reactivity to the antibodies were used as positive controls. Specimens in which the primary antibody was replaced with normal serum of the same isotype as the primary antibody served as negative control.

The density of MCs in the different oral lesions was expressed as the mean number of positive cells in an area of $56 \mu \mathrm{m} / \mathrm{mm}^{2}$. Brown staining of the cells indicated positive cases. The shape of the cells and their degranulation were also evaluated $[12,13,15,16]$. The density of microvessels in the lesions was expressed as the mean number of vessels per area $\left(56 \mu \mathrm{m} / \mathrm{mm}^{2}\right)$ at $200 \times$ magnification [16]. Positive cases were identified by brown staining of endothelial cells in hot spot areas.

Two trained observers (S.V.F. and J.N.S.) performed the histomorphometric analysis under a high-definition light microscope (Axiostar Plus, Zeiss, Germany) at $400 \times$ magnification. Up to 10 fields were examined and the images were captured with a camera (Axiocam Icc3, Zeiss). Blood vessel density and MC counts per square millimeter were obtained by using a specific software (Axiovision Rel 4.8, Zeiss, 2008) and the arithmetic mean was determined for each case. Microvessels were counted and those with a lumen $>50 \mu \mathrm{m}$ were excluded [29]. Both observers were unaware of the microscopic diagnosis and immunohistochemical analysis was performed in a blind manner.

Differences between groups were evaluated by ANOVA, followed by the Tukey test. Correlations were determined by Pearson's test. All statistical analyses were performed using the Minitab 14 program (Pennsylvania, USA). A p value $<0.05$ was considered statistically significant.

\section{Results}

All of reactive lesions (FH, IFH, PGCL) showed a predilection for females $(68.86 \%)$ and the age ranged from 15 to 80 years (mean 46.93; $\mathrm{DP} \pm 18.44)$. There was a wide variation in the site affected including buccal mucosa (16\%), gingiva (16\%) and alveolar edge ( $8 \%)$ and lower lip (5\%). With respect to CGCL, there was a male predominance (60\%) with age ranging from 8 to 19 years (mean 13 years, $\mathrm{DP} \pm 18.44$ ). The most affected anatomical location was the mandible. Some cases were not included due to lack of information.

Mast cells were detected in all lesions studied and exhibited varied morphology (oval, elongated or round). In general, MCs were found near blood vessels and in areas of fibrosis. In cases of $\mathrm{FH}$, MCs were located around blood vessels (Fig. 1A). In the presence of inflammation, MCs were also detected in these areas (Fig. 1B, C). In $\mathrm{LCH}$, the MC population was found in stromal areas, more specifically in fibrous areas (Fig. 1D). Some areas showed MCs entrapped inside the lobes, but always near blood vessels (Fig. 1E, F). In PGCL, MCs were clearly seen concentrated in the band of lamina propria, which separated the lesion (Fig. 1G), and around areas of ulceration. Sometimes, this cell population was located in bands of fibrous stroma and amidst multinucleated giant cells, but this finding was rare (Fig. 1H). In CGCL, MCs were more concentrated in fibrous areas that separated groups of multinucleated giant cells (Fig. 1I) rather than close to stromal proliferations of giant cells (Fig. 1J). Mast cells were often seen in the epithelial lining of some lesions (Fig. 1C, D).

Degranulation of MCs was observed mainly in IFH cases $(n=9$; Fig. 1E) and was rare in $\mathrm{FH}(\mathrm{n}=4)$. Degranulation was also present in cases of $\mathrm{LCH}(\mathrm{n}=3)$ and $\mathrm{CGCL}(\mathrm{n}=3)$, and was observed near bone tissue in CGCL.

In cases of PGCL, degranulation was not seen in areas inside the lesion. However, degranulation was present around the lesions. 

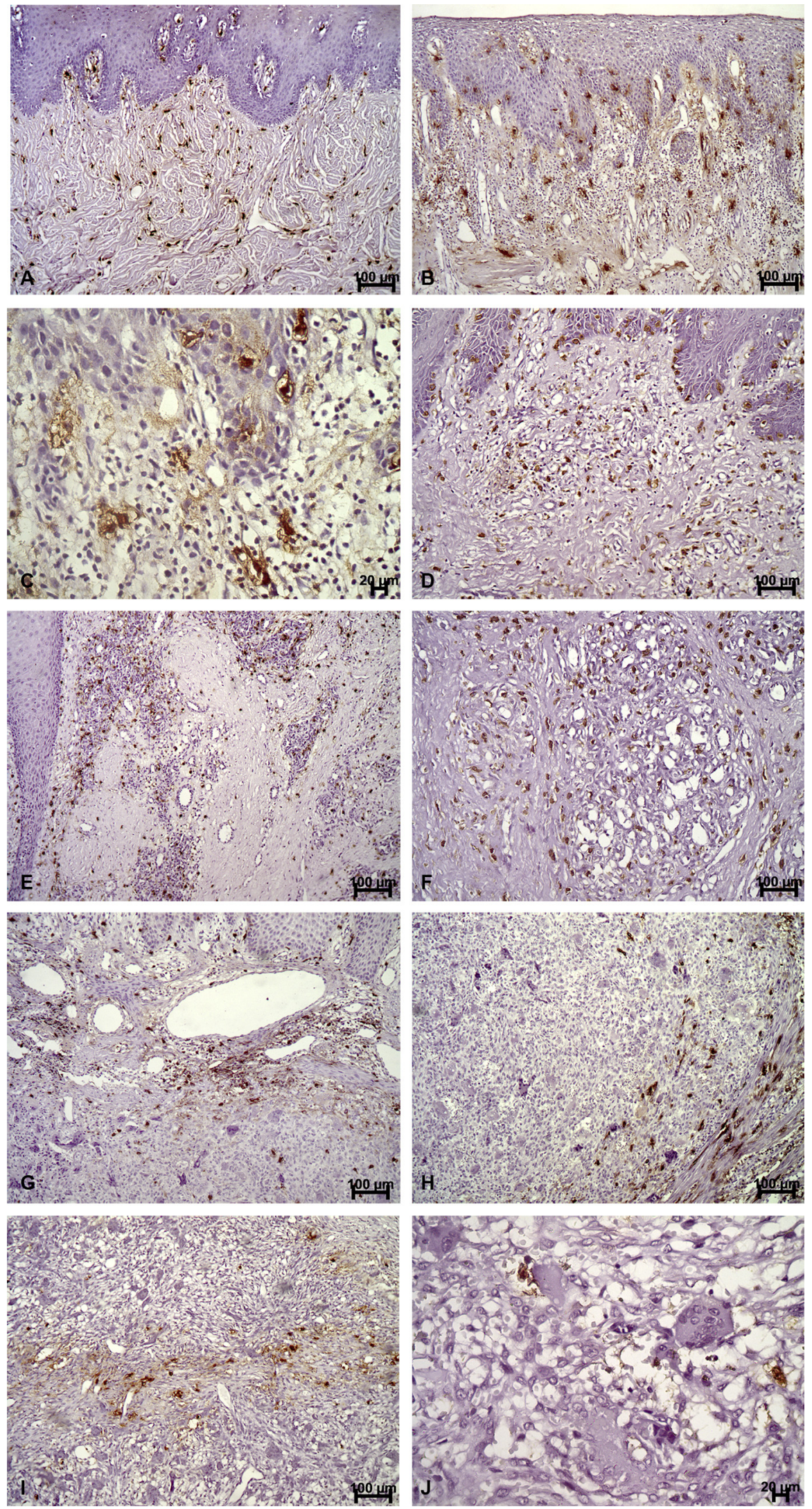

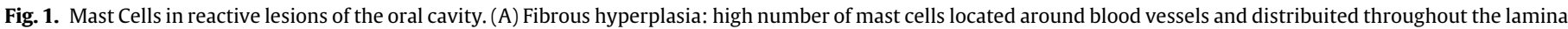

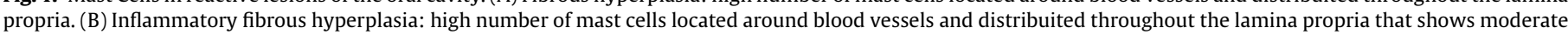

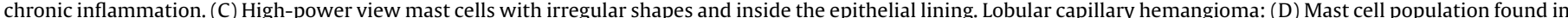

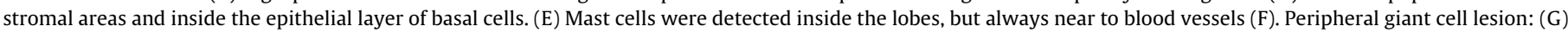

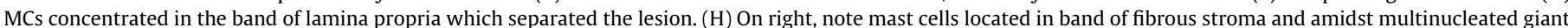

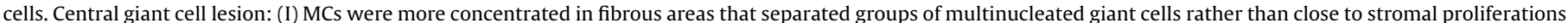
of giant cells $(\mathrm{J})$. 
Table 1

Mean density $/ \mathrm{mm}^{2}$ of mast cells and microvessels in fibrous hyperplasia, inflammatory fibrous hyperplasia, lobular capillary hemangioma, peripheral giant cell lesion, and central giant cell lesion.

\begin{tabular}{lll}
\hline Reactive Lesions & Expression of Mast Cells & Expression of CD34 \\
\cline { 2 - 3 } & Mean (SD) & Mean (SD) \\
\hline FH & $13.93(10.49)^{\mathrm{bg}}$ & $10.23(4.19)^{\mathrm{af}}$ \\
IFH & $15.01(4.47)^{\mathrm{cf}}$ & $13.05(10.10)^{\mathrm{e}}$ \\
LCH & $37.01(21.30)^{\mathrm{abce}}$ & $21.69(7.49)^{\mathrm{abd}}$ \\
PGCL & $12.45(7.10)^{\mathrm{ad}}$ & $9.15(3.33)^{\mathrm{bc}}$ \\
CGCL & $8.14(3.37)^{\mathrm{defg}}$ & $6.24(2.94)^{\mathrm{cdef}}$ \\
\hline
\end{tabular}

One-way ANOVA ( $p=0.000$ for mast cells and $p=0.001$ for CD34). ${ }^{*}$ The same letters indicate mean values between lesions differ significantly by ANOVA. FH: fibrous hyperplasia; IFH: inflammatory fibrous hyperplasia; LCH: lobular capillary hemangioma; PGCL: peripheral giant cell lesion; CGCL: central giant cell lesion. SD: standart deviation.

Table 2

Correlation between the population of mast cells and microvessels in each reactive lesion, central giant cell lesion, and reactive lesions as a whole.

\begin{tabular}{lll}
\hline Variable & $\mathrm{r}$ & $p$ value \\
\hline FH & 0.246 & 0.494 \\
IFH & 0.636 & $0.048^{\mathrm{a}}$ \\
LCH & 0.447 & 0.315 \\
PGCL & 0.292 & 0.413 \\
CGCL & 0.973 & $0.005^{\mathrm{a}}$ \\
RL & 0.653 & $0.005^{\mathrm{a}}$
\end{tabular}

Pearson's test. FH: fibrous hyperplasia; IFH: inflammatory fibrous hyperplasia; LCH: lobular capillary hemangioma; PGCL: peripheral giant cell lesion; CGCL: central giant cell lesion; RL: reactive lesions as a whole.

a Statistically significant.

Differences in the number of MCs were observed between the different types of lesions studied $(p=0.000$ ) (Table 1$)$. Significant differences were found between LCH versus CGCL $(p=0.012), \mathrm{LCH}$ versus PGCL $(p=0.026)$, LCH versus FH $(p=0.029)$, and $\mathrm{LCH}$ versus IFH $(p=0.036)$. A higher MC density was observed in LCH (37.01), while CGCL exhibited the lowest density (8.14). There was a significant difference in $\mathrm{MC}$ density when all reactive lesions were compared to CGCL $(\mathrm{p}=0.001)$.

Microvessels were detected in all lesions studied and were concentrated in stromal tissue. Their morphology was variable and some showed a collapsed lumen. CD34 staining of occasional stromal cells was observed in most lesions (Fig. 2A-E).

Differences in the number of microvessels were observed between the lesions studied (Table 1 ). This difference was only significant when LCH was compared individually to FH $(p=0.006)$, $\operatorname{PGCL}(\mathrm{p}=0.004)$, and CGCL $(\mathrm{p}=0.001)$. The largest mean number of microvessels was observed in LCH (21.69), followed in decreasing order by IFH, FH, and PGCL. The smallest number was observed in CGCL (6.24). There was a significant difference in microvessel density when the reactive lesions were compared to CGCL ( $p=0.003)$.

Individual analysis of each type of lesion showed a direct correlation between the presence of MCs and microvessels, but this difference was significant only for IFH $(p=0.048)$ and CGCL $(\mathrm{p}=0.005)$ (Table 2$)$. A direct and significant correlation between the number of MCs and microvessels $(p=0.005)$ was also observed when the reactive lesions were analyzed as a whole (Table 2 ).

\section{Discussion}

Our results showed that the reactive lesions studied differ significantly from CGCL in terms of mean MC and microvessel density. To our knowledge, this is the first study to perform an immunohistochemical analysis of MCs and microvessels in oral reactive lesions.
In this study, we used mast cell tryptase and CD34 to identify MCs and microvessels, respectively, as established in previous studies $[12,13,15,16]$. There are other studies on reactive lesions [30,31], but these have used toluidine blue. Despite the importance of this histochemical technique, comparative analysis is necessary since differences may exist between immunohistochemical and histochemical techniques.

There is consensus among studies regarding the distribution of MCs around blood vessels $[1,11,15]$ and this was confirmed in the present study. Mast cells were frequently observed in areas of ulceration and inflammation, as reported in previous studies $[11,15]$ including reactive lesions [31-33]. However, this cell population was also seen in areas of fibrosis even in the absence of inflammation. This finding has also been reported in other studies on FH lesions [30-32]. The presence of MCs in areas of fibrosis may be attributed to the fact that their granules are rich in proteases, including tryptase [4]. Furthermore, an in vitro study showed that MCs accelerate the migration and proliferation of fibroblasts [2] and another study demonstrated the stimulation of collagen synthesis by human MCs [5]. Previous studies from our team also showed the contribution of MCs to collagen synthesis in tissue repair [11] and in neoplasms [12,13]. Moreover, the presence of MCs in the epithelial lining of some reactive lesions suggests a role in antigen presentation, demonstrating the active growth of these lesions since MCs express class II major histocompatibility complex (MHC) molecules [34].

Specifically, in addition to the present study showing a significant quantitative difference in mean MC density between all reactive lesions and $\mathrm{CGCL}$, individually $\mathrm{LCH}$ showed significant quantitative differences between the cases of FH and IFH. Although other authors found a larger number of MCs in peripheral ossifying fibroma and IFH [30,31], in this study the mean density of this cell population was higher in LCH followed by IFH. This larger number of MCs may be attributed to the presence of ulceration in all cases of LCH, but other areas distant from the ulceration also harbored MCs; nevertheless, we are dealing with a reactive lesion. On the other hand, Reddy et al. [30] found a larger number of MCs in pyogenic granuloma.

It is important to note that degranulated MCs somehow played a role in all reactive lesions. This fact may indicate that the lesions are constantly growing and this cell population is responsible for the remodeling and expansion of connective tissue $[12,13,33]$ and possible local destruction in CGCL.

MCs are usually found in association with blood vessels, they are related to angiogenesis [1,35]. In this respect, several studies have demonstrated that MCs are a rich source of different potent angiogenic factors, such as VEGF $[1,6,35]$. In the present study, LCH exhibited a significantly higher mean microvessel density than the other reactive lesions. We believe that this result is due to the origin of $\mathrm{LCH}$, which is a proliferative angiomatous and reactive lesion. The difference was also significantly greater in reactive lesions than in CGCL. Similar results have been reported by Matos et al. [36], who found a higher VEGF-positive microvessel count in PGCL than in CGCL. According to Peacock et al. [37], angiogenesis seems to contribute to the aggressiveness of CGCL, however, it is not possible to clarify this matter in the present study.

Although differences in microvessel density exist as described previously, this study also showed a positive correlation between MCs and CD34-positive microvessels in all reactive lesions analyzed, as well as in CGCL. This finding suggests that MCs contribute to angiogenesis and to the development of these lesions. Although these stromal components contribute to the development of reactive lesions, and allow to distinguish these lesions from CGCL, further studies are needed to understand the role of MCs and microvessels in CGCL, a potentially aggressive lesion $[1,36,38]$. 

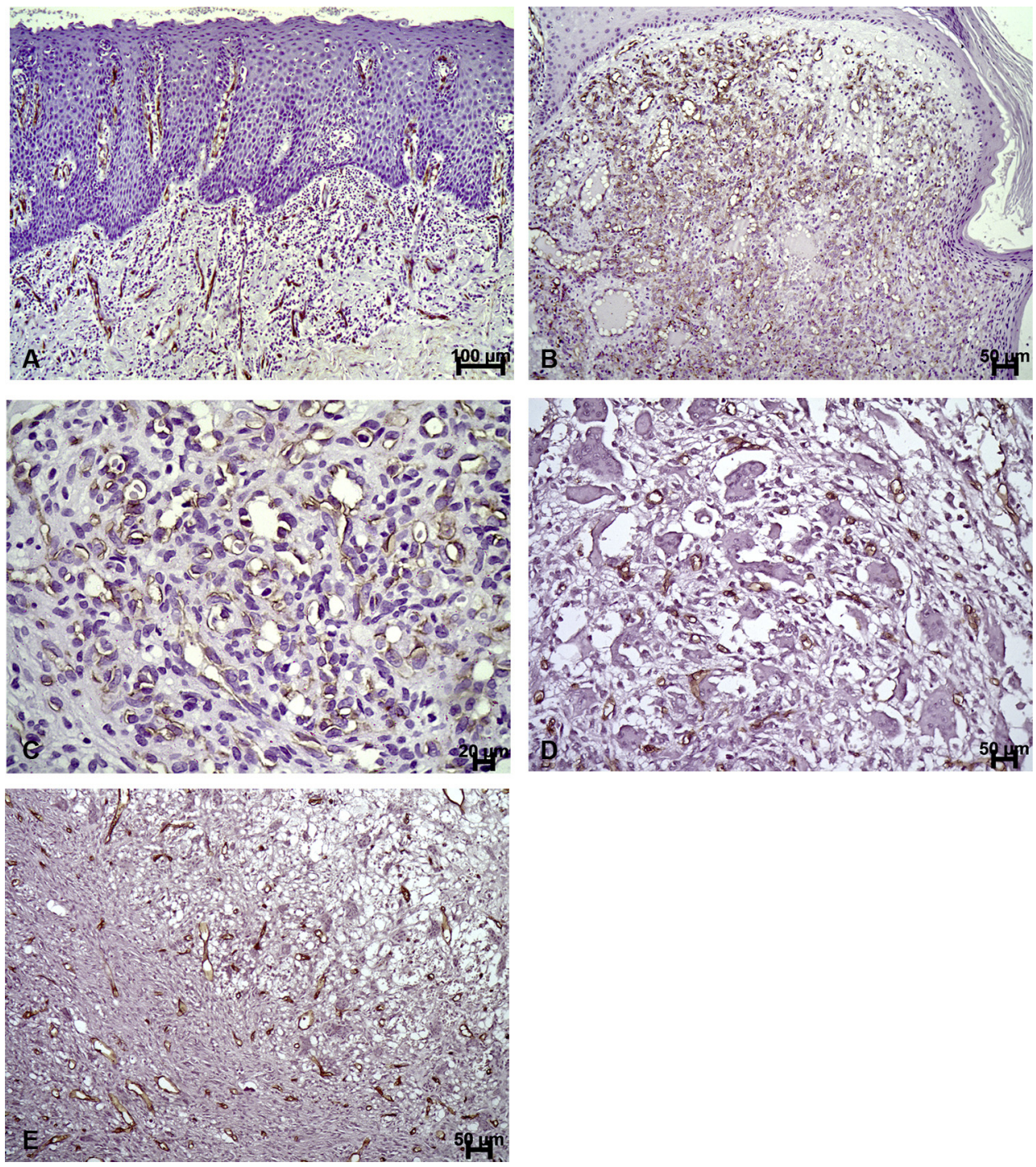

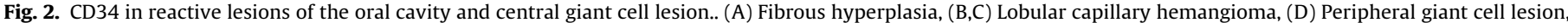
(E) Central giant cell lesion.

Finally, mast cells might contribute to the connective tissue framework and angiogenic function, as well as the development, of reactive lesions of the oral cavity, such as FH, IFH, LCH and PGCL. Despite the correlation of these stromal components with CGCL, lower mean values were observed in these lesions. Further studies are needed to better understand the pathogenesis of CGCL.

\section{Acknowledgment}

We thank CNPq for financial support.

\section{References}

[1] K. Norrby, Mast cells and angiogenesis, APMIS 110 (2002) 355-371.

[2] F. Levi-Schaffer, A. Kupietzky, Mast cells enhance migration and proliferation of fibroblasts into an in vitro wound, Exp. Cell. Res. 188 (1990) 42-49.

[3] S. Huang, T. Ling. H. Wu, Experimental study on aqueous areca nut extracts inducing oral submucous fibrosis in rats. II. Effection of mast cells on collagen metabolism, Hua Xi Kou Qiang Yi Xue Za Zhi 15 (1997) 94-96.

[4] J. Gailit, M.J. Marchese, R.R. Kew, B.L. Gruber, The differentiation and function of myofibroblasts is regulated by mast cell mediators, J. Invest. Dermatol. 117 (2001) 1113-1119.

[5] E. Garbuzenko, A. Nagler, D. Pickholtz, P. Gillery, R. Reich, F.X. Maquart, F Levi-Schaffer, Human mast cells stimulate fibroblast proliferation, collagen synthesis and lattice contraction: a direct role for mast cells in skin fibrosis, Clin. Exp. Allergy 32 (2002) 237-246.
[6] E. Crivellato, C.A. Beltrami, F. Mallardi, D. Ribatti, The mast cell: an active participant or an innocent bystander? Histol. Histopathol. 19 (2004) 259-270.

[7] H.-W. Wang, N. Tedla, J.E. Hunt, D. Wakefield, H.P. McNeil, Mast cell accumulation and cytokine expression in the tight skin mouse model of scleroderma, Exp. Dermatol. 14 (2005) 295-302.

[8] M. Walker, R. Harley, E.C. LeRoy, Ketotifen prevents skin fibrosis in the tight skin mouse, J. Rheumatol. 17 (1990) 57-59.

[9] U. Noyan, S. Yilmaz, O. Arda, B. Kuru, The ultrastructural examination of gingival fibromatosis, J. Marmara. Univ. Dent. Fac. 2 (1994) 409-413.

[10] F.N. Skopouli, L. Li, D. Boumba, S. Stefanaki, K. Hanel, H.M. Moutsopoulos, S.A. Krilis, Association of mast cells with fibrosis and fatty infiltration in the minor salivary glands of patients with Sjögren's syndrome, Clin. Exp. Rheumatol. 16 (1998) 63-65.

[11] I.C. De Castro, C.A. Rocha, A.C. Gomes Henriques, A.P. Cavalcanti de Sousa, M.V. Lisboa, R. Sotero Dda, A.L. Pinheiro, P.R. Cury, J.N. Santos, Do laser and led phototherapies influence mast cells and myofibroblasts to produce collagen? Lasers Med. Sci. 29 (2014) 1405-1410.

[12] F. de Assis Caldas Pereira, C.A. Gurgel, E.A. Ramos, M.T. Vidal, A.L. Pinheiro, V. Jurisic, C.B. Sales, P.R. Cury, J.N. dos Santos, Distribution of mast cells in benign odontogenic tumors, Tumour Biol. 33 (2012) 455-461.

[13] M.T. Vidal, I.B. de Oliveira Araújo, C.A. Gurgel, A. Pereira Fde, D.S. Vilas-Bôas, E.A. Ramos, I.M. Agra, A.C. Barros, V.S. Freitas, J.N. Dos Santos, Density of mast cells and microvessels in minor salivary gland tumors, Tumour Biol. 34 (2013) 309-316.

[14] I. Feoktistov, S. Ryzhov, A.E. Goldstein, I. Biaggioni, Mast cell-mediated stimulation of angiogenesis: cooperative interaction between $\mathrm{A} 2 \mathrm{~B}$ and $\mathrm{A} 3$ adenosine receptors, Circ. Res. 92 (2003) 485-492.

[15] C.P. Araújo, C.A. Gurgel, E.A. Ramos, V.S. Freitas, A. Barbosa Ade Jr. L.M. Ramalho, J.N. dos Santos, Accumulation of CD1a-positive Langerhans cells and mast cells in actinic cheilitis, J. Mol. Histol. 41 (2010) 357-365. 
[16] J.G. Conceição, C.A. Gurgel, E.A. Ramos, F.C. De Aquino Xavier, C.B. Schlaepfer-Sales, M.C. Cangussu, P.R. Cury, L.M. Ramalho, J.N. Dos Santos, Oral mucoceles: a clinical, histopathological and immunohistochemical study, Acta Histochem. 116 (2014) 40-47.

[17] Z.K. Otrock, R.A.R. Mahfouz, J.A. Makarem, A.I. Shamseddine, Understanding the biology of angiogenesis: review of the most important molecular mechanisms, Blood Cells Mol. Dis. 39 (2007) 212-220.

[18] A. Bataineh, Z.N. Al-Dwairi, A survey of localized lesions of oral tissues: a clinicopathological study, J. Contemp. Dent. Pract. 6 (2005) 30-39.

[19] N.J. Naderi, N. Eshghyar, H. Esfehanian, Reactive lesions of the oral cavity: A retrospective study on 2068 cases, Dent. Res. J. (Isfahan) 9 (2012) 251-255.

[20] F.R. de Matos, T.G. Benevenuto, C.F.W. Nonaka, L.P. Pinto, L.B. de Souza, Retrospective analysis of the histopathologic features of 288 cases of reactional lesions in gingiva and alveolar ridge, Appl. Immunohistochem. Mol. Morphol. 22 (2014) 505-510.

[21] P.G. Peralles, A.P.B. Viana, A.L.R. Azevedo da, F.R. Pires, Gingival and alveolar hyperplasticreactive lesions: clinicopathologicalstudy of 90 cases, Brazilian J. Oral Sci. 5 (2006) 1085-1089.

[22] V.I. Akinmoladun, O.B. Akintububo, A.O. Adisa, E.O. Ojo, D. Ayuba, Evaluation of the histopathology of orofacial lesions in a North-East Nigerian tertiary centre, Ann. Afr. Med. 12 (2013) 105-109.

[23] B. Kashyap, P.S. Reddy, P. Nalini, Reactive lesions of oral cavity: A survey of 100 cases in Eluru, West Godavari district, Contemp. Clin. Dent. 3 (2012) 294-297.

[24] M. Toida, T. Hasegawa, F. Watanabe, K. Kato, H. Makita, H. Fujitsuka, Y. Kato, K. Miyamoto, T. Shibata, K. Shimokawa, Lobular capillary hemangioma of the oral mucosa: clinicopathological study of 43 cases with a special reference to immunohistochemical characterization of the vascular elements, Pathol. Int. 53 (2003) $1-7$.

[25] S.R. Lester, K.G. Cordell, M.S. Rosebush, A.A. Palaiologou, P. Maney, Peripheral giant cell granulomas: a series of 279 cases, Oral Surg. Oral Med. Oral Pathol. Oral Radiol. 118 (2014) 475-482.

[26] F.M. Jadu, M.J. Pharoah, L. Lee, G.I. Baker, A. Allidina, Central giant cell granuloma of the mandibular condyle: a case report and review of the literature, Dentomaxillofac Radiol. 40 (2011) 60-64.

[27] N. Eivaz, V. Patel, W.O. Collins, A rapidly enlarging maxillary lesion. Left maxillary giant cell reparative granuloma (GCRG), JAMA Otolaryngol. Head Neck Surg. 141 (2015) 287-288.
[28] R. Chuong, L.B. Kaban, H. Kozakewich, A. Perez-Atayde, Central giant cell lesions of the jaws: a clinicopathologic study, J. Oral Maxillofac. Surg. 44 (1986) 708-713.

[29] D. Guttman, Y. Stern, T. Shpitzer, D. Ulanovski, T. Druzd, R. Feinmesser, Expression of MMP-9, TIMP-1, CD-34 and factor-8 as prognostic markers for squamous cell carcinoma of the tongue, Oral Oncol. 40 (2004) 798-803.

[30] V. Reddy, S.S. Bhagwath, M. Reddy, Mast cell count in oral reactive lesions: A histochemical study, Dent. Res. J. (Isfahan) 11 (2014) 187-192.

[31] S.S. Farahani, A. Navabazam, F.S. Ashkevari, Comparison of mast cells count in oral reactive lesions, Pathol. Res. Pract. 206 (2010) 151-155.

[32] M. Kiuchi, T. Yamamura, M. Okudera, V. Souksavanh, T. Ishigami, T. Iwase, S. Warnakulasuriya, K. Komiyama, An assessment of mast cells and myofibroblasts in denture-induced fibrous hyperplasia, J. Oral Pathol. Med. 43 (2014) 53-60.

[33] P.P. Santos, C.F. Nonaka, L.P. Pinto, L.B. de Souza, Immunohistochemical expression of mast cell tryptase in giant cell fibroma and inflammatory fibrous hyperplasia of the oral mucosa, Arch. Oral Biol. 56 (2011) 231-237.

[34] H. Vincent-Schneider, C. Théry, D. Mazzeo, D. Tenza, G. Raposo, C. Bonnerot, Secretory granules of mast cells accumulate mature and immature MHC class II molecules, J. Cell Sci. 114 (2001) 323-334.

[35] S.C.A. Lima, V.H.T. Rizo, Y.T.C. Silva-Sousa, L.Y. Almeida, O.P. Almeida, J.E. León, Immunohistochemical evaluation of angiogenesis and tryptase-positive mast cell infiltration in periapical lesions, J. Endod 37 (2011) 1642-1646.

[36] F.R. Matos, C.F. Nonaka, M.C. Miguel, H.C. Galvão, L.B. de Souza, A. Freitas Rde Immunoexpression of MMP-9, VEGF, and vWF in central and peripheral giant cell lesions of the jaws, J. Oral Pathol. Med. 40 (2011) 338-344.

[37] Z.S. Peacock, R.C.K. Jordan, B.L. Schmidt, Giant cell lesions of the jaws: does the level of vascularity and angiogenesis correlate with behavior? J. Oral Maxillofac. Surg. 70 (2012) 1860-1866.

[38] M. Vered, A. Buchner, D. Dayan, Giant cell granuloma of the jawbones? a proliferative vascular lesion? Immunohistochemical study with vascular endothelial growth factor and basic fibroblast growth factor, J. Oral Pathol. Med. 35 (2006) 613-619. 